\title{
An Integrated Decision Support Model For Enhancing Continuous Improvement Of Academic Programs
}

\author{
Mohammed Al-Shargabi \\ Department of Information Systems, \\ College of Computer Science and Information Systems, \\ Najran University, Najran, Saudi Arabia \\ mashargabi@nu.edu.sa
}

\begin{abstract}
Continuous Quality Improvement (CQI) in higher educational institutions is considered an aspect that plays a vital role in maintaining excellence in teaching and learning. It focuses on several critical phases such as designing Program Learning Outcomes (PLOs) assessment plans, collecting data, evaluating the of PLO achievement results, and designing and implementing improvement actions to achieve educational goals. CQI is very critical to assess and improve the educational process. As it appears, academic program decision-makers find difficult to formulate and implement an authentic CQI for their programs without the help of decision support systems (DSSs). Therefore, this paper proposes an integrated decision support model that provides CQI decision support to enhance academic programs. Moreover, it provides authentication of the CQI process by autochecking the accuracy of the CQI phases (assessment, evaluation, designing, and implementing improvement). After the development and implementation of the proposed model in a bachelor-level academic institution, the results show that the proposed model provides decision support for enhancing academic program's CQI, and authentication of the CQI accuracy, which will lead to the improvement of the educational process and the achievement of educational goals.
\end{abstract}

Keywords-decision support model; academic programs; continuous quality improvement; program learning outcomes; assessment plan; improved education outcomes

\section{INTRODUCTION}

Continuous quality improvement in academic programs has been a matter of international interest as a method for ongoing program quality enhancement [1]. CQI allows academic programs to improve the effectiveness of the education process based on actual student achievement, ensures that students learn the most important skills needed in the job market, showcases the quality and accountability of the program for employers, donors, and accreditation agencies [2]. Moreover, CQI is considered as a core aspect in the Outcome Based Education (OBE) system [3]. OBE system mainly focuses on learning outcomes (what students should know, understand, and be able to do at the end of the education process). These learning outcomes are mainly attained through predefined learning activities integrated in program courses [4]. Courses are built intentionally towards attaining PLOs. A common approach to designing an academic program is constructive alignment [5], in which course, learning outcomes, teaching strategies, and learning outcomes assessment strategies are aligned together to support the achievement of PLOs. Thus, a program of the CQI process should be designed to be PLOcentered, and focus on several critical processes around PLOs, such as planning and designing of PLOs assessment, collecting data and evaluating the results of PLOs achievement, designing and implementing improvement strategies to attain PLOs. However, designing and implementing a PLO-centered CQI needs a continuous engagement of faculty, students, staff and administration. International projects have been proposed [6-8] to build a CQI for academic programs. Nevertheless, building an authentic CQI remains a difficult and complex task [2]. Decision-makers find it difficult to have an authentic CQI for their programs without the support of systematic decisionmaking [9] aid.

Authors in [10] proposed an adaptive decision support system (DSS) for higher learning institutions resource planning. The proposed DSS helps decision-makers in solving resource allocation planning problems. However, it does not support decision-makers to obtain outcome achievement. Authors in [11] proposed a DSS approach for higher educational institutions accreditation processes. The proposed approach assists the accreditation councils to automatic accreditation operations. It also classifies institutions into three categories, depending on the rules of accreditation councils. Hence, this approach cannot assist higher academic educational programs in improving the learning outcome achievement. Authors in [12] proposed a DSS that suggests suitable courses to be selected by the prospective students based on their academic ability. However, the proposed system cannot assist higher academic educational programs to improve their learning outcome. Authors in [13] conducted a questionnaire survey about the requirements of applying DSSs in Palestinian higher education institutions. The results showed that the level of approval for applying DSSs was $69.73 \%$. As a conclusion, they recommended higher educational institutions to rely on DSSs. Authors in [14] developed a multi-criteria DSS for evaluating knowledge, starting with members of higher educational institutions and ending with people of lower educational background. The research supports higher educational institutions with applied techniques to make strategic decisions in order to transfer knowledge to the society. 


\section{ACADEMIC PROGRAM CQI FRAMEWORK OVERVIEW}

The identification of the elements of CQI is facilitated in [15]. A common definition and elements of CQI are better practices in assessing and evaluating the extent to which PLOs are being attained. The results of these evaluations must be systematically utilized for the continuous improvement of the program. Figure 1 shows a high-level view of our continuous improvement framework. The PLOs assessment plan is the first step in the framework followed by PLOs evaluation to produce an attainment level of each PLO. Using the evaluation results of PLOs, improvement plans, including a set of actions that might affect any aspects of the program, are designed, approved and implemented to ensure a systematic quality assurance system. Authors in [2] propose a modified CQI approach where four underlying concepts are proposed: quality enhancement, constructive alignment, authentic assessment of the Structure of the Observed Learning Outcome (SOLO) taxonomy. In the Higher Education Quality Council of Ontario proposed model, quality enhancement concept denotes building institutional cultures that reflect the learning-centeredness and effectiveness of policies and practices for student success.

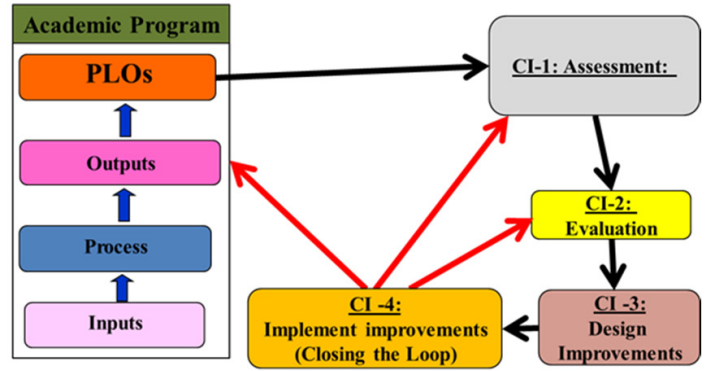

Fig. 1. Generic continuous improvement framework based on SOLO outcome-based assessment

It recommends assessment for the purposes of continually improving programs. Constructive alignment ensures that the entire program is constructively aligned. Assessment aims to provide straight indication of the actual students' performance. SOLO taxonomy suggests a gradual method to enunciate the complexity of learning outcomes as students' progress through a program. HEQCO proposes a model for creating assessment plans of PLOs as shown in Figure 2. It consists of a four-stage cycle: In STAGE 1 expectations are identified, STAGE 2 maps the assessment tasks, STAGE 3 gathers and analyzes the assessment results, and STAGE 4 makes program improvements.

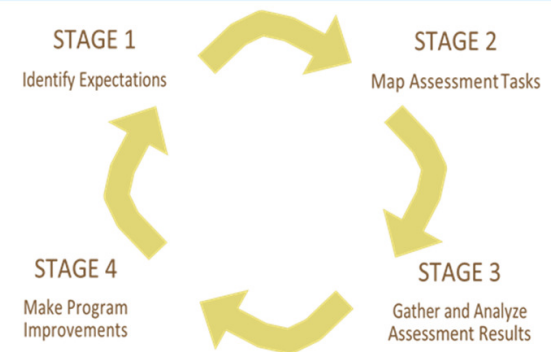

Fig. 2. HEQCO model for creating assessment plan of PLOs
However, the HEQCO model does not provide decision support guide for PLO CQI, nor does it propose any applied steps to check the CQI accuracy. Thus, there is a need for a DSS model for CQI, one that contains applied steps to check the authentication of the CQI accuracy. In [16], a decision support approach for continuous improvement at the course level is proposed, which cannot support the CQI needs at the program level. Thus, this paper will enhance the approach in [16] in order to be suitable for a decision support model that can fit the CQI needs at the program level.

\section{INTERGRATED DSS MODEL FOR ENHANCING CONTINUOUS IMPROVEMENT OF ACADEMIC PROGRAM LEARNING ACHIEVEMENTS}

An important factor in order to build an authentic CQI model is to have an authentic assessment process. Thus, an integrated PLO assessment plan framework is proposed that can fit with the integrated decision support to enhance the continuous improvement of academic programs and formulate authentic CQI. The proposed integrated PLO assessment plan framework uses multi-assessment methods to build a CQI. The proposed framework maximizes validity and reduces the bias in the CQI of PLOs by using direct, indirect, formative, and summative assessment methods. This framework consists of two main assessment cycles which are: formative cycle using the assessment of Course Learning Outcomes (CLOs) in the courses located in the middle of the program study plan, assessment of Formative Performance Indicators (FPIs) (a set of PIs that describe PLO in a more measurable and specific way), and a survey on current students about PLO achievement. The second assessment cycle is a summative cycle using the assessment of CLOs in the courses located at the end of the program study plan, assessment of Summative Performance Indicators (SPIs), and a graduate student survey about PLO achievement. The proposed integrated PLO assessment plan allows conducting authentic assessment process and also builds an authentic CQI by adhering to the following steps:

- Assessing the PLO (formative cycle) to give an indicator about the PLO achievement in early stages and discovering any obstacles that might hinder early PLO attainment.

- Helps formulating an early PLO improvement plan.

- Checking the accuracy and efficiency of the assessment and evaluation process by comparing the results of CLO assessment and PI assessment.

- Checking the accuracy and efficiency of the continuous improvement process by comparing the results of summative and formative assessment, where the data for summative assessment were collected after the formative assessment.

The proposed framework uses CLO assessment because all courses are mapped to the appropriate PLOs by relating CLOs of all courses to PLOs. Mapping courses to PLOs ensures that all PLOs are addressed by several courses at different levels in the program. In addition, this will help to know if a PLO was not achieved at a particular course. On the other hand, the proposed framework uses PIs with Rubrics assessment, due to 
the fact that PIs can give direct indicators about PLOs and facilitate the collection of data. The data are then evaluated by using a set of rubrics. The proposed framework uses CLOs, and PIs assessment as direct assessment to get a direct examination or observation of student performance and PLO achievement. In addition, it uses exit surveys as an indirect assessment method to get students' opinion on the PLOs achievement. Moreover, the proposed framework uses formative assessments for on-going assessments, reviews, and observations in the middle of the student's studies. The aim of formative assessment is to monitor student PLO achievement in early stages and provide an ongoing feedback which can be used to enhance students' performance. In addition, the proposed framework uses summative assessments to evaluate the effectiveness of programs and PLO achievement at the end of the studying period. The goal of summative assessments is to make a judgment of students' competency after an instructional phase is complete. Figure 3 shows the proposed integrated PLO assessment plan framework conceptual model.

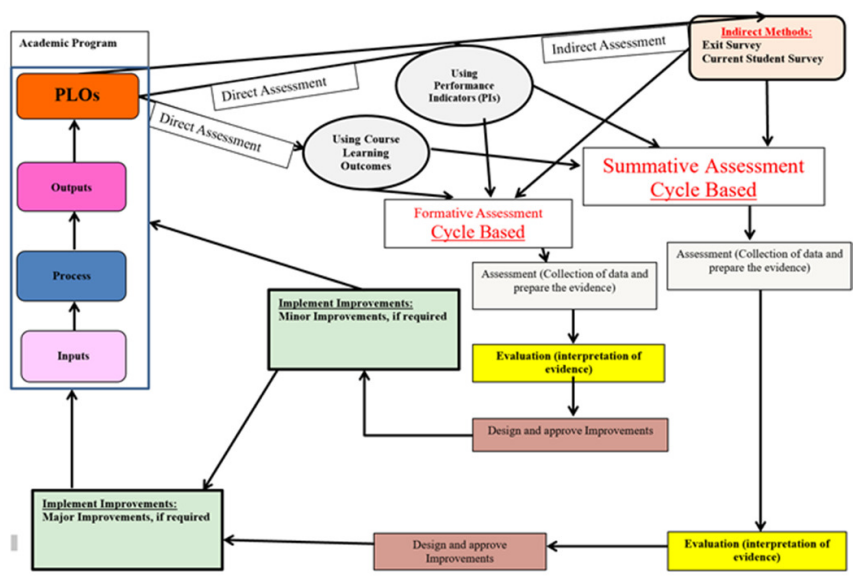

Fig. 3. Integrated PLOs assessment plan framework conceptual model

The proposed integrated PLOs assessment plan framework will be used in the proposed integrated decision support model for enhancing continuous improvement of academic programs learning achievement to help in conducting authentic CQI. The proposed model is based on systematic steps to build and implement a decision support model for CQI that contains applied steps to check the authentication of the CQI accuracy through mathematical equations. Figure 4 shows the flowchart of the proposed model of CQI decision support which includes the following steps:

- Identifying the PLOs: identifying what the learners are supposed to know, understand, and be able to do by the end of the program.

- Pinpointing the assessment timeline: identifying the assessment cycle duration (specifying formative assessment cycle duration and/or summative assessment cycle duration).

- Specifying the time of collection, evaluation, and improvements: is about which semester will the data regarding PLO will be collected, evaluated, and improvement actions will be implemented.

- Identifying assessment tasks: identifying the detailed information of each assessment method/tools as shown in Table I.

- Creating the PLO assessment plan: guideline for all assessment and evaluation steps as shown in Figure 3.

- Using curriculum mapping: to identify the courses at which the program might collect assessment data for specific PLOs.

- Conducting formative assessment plans using CLOs, and PIs: asking questions about the CLOs in the courses located in the middle of the program study plan, questions about the FPIs, and a survey about the current students' PLOs achievement

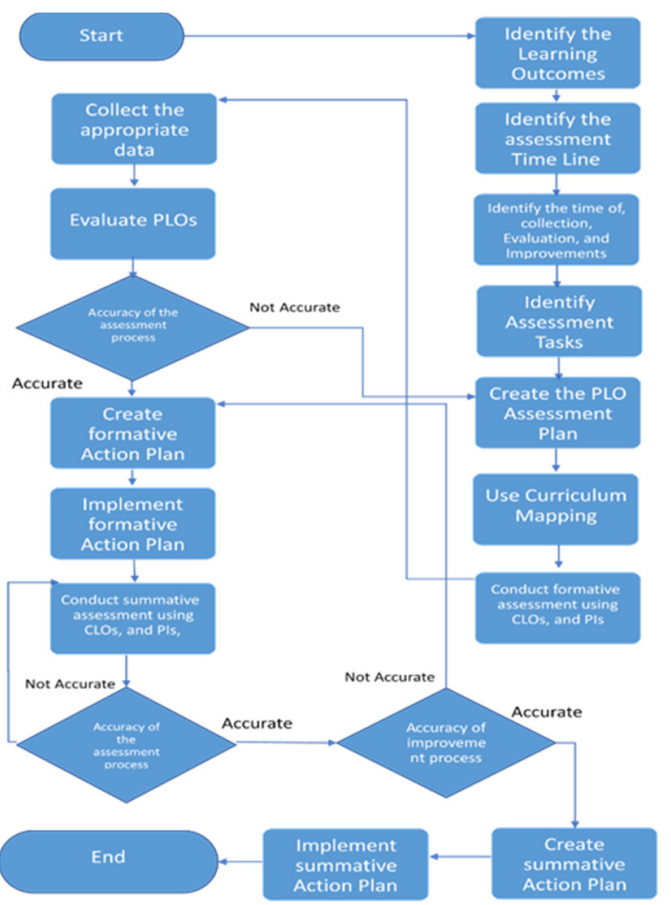

Fig. 4. The flowchart of the proposed model of CQI decision support

TABLE I. ASSESSMENT TASK INFORMATION

\begin{tabular}{|c|c|c|c|c|}
\hline \multirow{2}{*}{ Assessment task } & \multicolumn{4}{|c|}{ Assessment Method/Tool } \\
\cline { 2 - 5 } & CLOs & PIs & Exit survey & $\begin{array}{c}\text { Current } \\
\text { students survey }\end{array}$ \\
\hline Direct/Indirect & Direct & Direct & Indirect & Indirect \\
\hline $\begin{array}{c}\text { Summative/ } \\
\text { Formative }\end{array}$ & Formative & Summative & Summative & Formative \\
\hline Time based & Cycle based & Cycle based & Cycle based & Cycle based \\
\hline $\begin{array}{c}\text { Where and } \\
\text { whom }\end{array}$ & $\begin{array}{c}\text { Senior } \\
\text { courses }\end{array}$ & $\begin{array}{c}\text { Junior } \\
\text { courses }\end{array}$ & $\begin{array}{c}\text { Gradation } \\
\text { projects }\end{array}$ & Senior courses \\
\hline Threshold & $50 \%$ & $50 \%$ & $80 \%$ & $80 \%$ \\
\hline
\end{tabular}

- Collecting the appropriate data: inserting the marks of the PLOs achievement based on the assessment tools. 
- Evaluating the PLOs: determines the extent to which PLOs are being attained.

- Checking the authentication of the formative assessment and the evaluation process by comparing the results of formative CLOs assessment in $\mathrm{PLO}_{\mathrm{F}_{-} \mathrm{Acv}_{\mathrm{CLO}}}$ and formative PIs assessment in $\mathrm{PLO}_{F_{-} A c V_{P I}}$ using:

$$
\text { if }\left(\mathrm{ABS}\left(\mathrm{PLO}_{\mathrm{F}_{-} \mathrm{Acv}_{\mathrm{CLO}}}-\mathrm{PLO}_{F_{-} \mathrm{Acv}_{\mathrm{PI}}}\right)<\mathrm{F}_{-} \mathrm{ACDiff}\right)
$$

formative assessment process was accurate Else

formative assessment process was not accurate (1)

where F_ACDiff is the acceptable value of the difference in formative assessment results.

- Creating a formative action plan: using the results of formative assessment cycle to have an early PLO improvement plan.

- Implementing the formative action plan: involves the implementation of the approved actions regarding the formative improvement plan.

- Conducting summative assessment using CLOs, and PIs: asking questions about the CLOs in the courses located in the end of the study plan, questions about the SPIs, and questions in the graduate student's survey about PLO achievement.

- Checking the authentication of the summative assessment and evaluation process by comparing the results of summative CLOs assessment in $\mathrm{PLO}_{\mathrm{S}_{-} \mathrm{Acv}_{\mathrm{CLO}}}$ and summative PIs assessment in $\mathrm{PLO}_{S_{-} A_{c V_{P I}}}$ using:

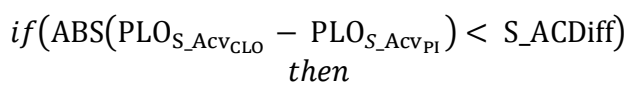

summative assessment process was accurate Else

summative assessment process was not accurate (2)

where S_ACDiff is the acceptable value of the difference in summative assessment results.

- Checking the authentication and efficiency of the CQI process by comparing the results of PLO summative assessment and PLO formative assessment by using the following:

$$
\begin{aligned}
& \text { if }\left(\mathrm{PLO}_{\mathrm{Acv}_{\text {sum }}} \geq \mathrm{PLO}_{\text {then }}\right. \\
& \text { CQI process was accurate } \\
& \text { Else } \\
& \text { CQI was not accurate }
\end{aligned}
$$

- Creating a summative action plan: using the results of summative assessment cycle to have a final PLO improvement plan.

- Implementing the summative action plan: involves the implementation of the approved actions in summative improvement plans.

\section{IMPLEMENTATION OF THE INTERGRADED DSS}

The proposed model has been implemented in a Bachelor level program starting from the first semester in the academic year 2016-2017 with collaboration of the head of the department, course instructors, and the assessment committee to validate the ability of the proposed model to provide decision support for CQI improvement at the program level, and provide decision support in improving their assessment, evaluation, and continuous improvement planning skills. The proposed model showed efficiency in auto evaluation of the achievement of the PLOs for all the assessment methods. Moreover, it shows efficiency in providing decision support in the enhancement of the PLO achievement for each assessment method. Figure 5 shows a general PLOs achievement report for all the PLOs which shows PLO achievement percentage for each assessment method with graphic presentation to show the achieved PLO in green color, and unachieved PLO in orange color. Figure 6 illustrates the general performance of PLOs evaluation for all the assessment methods. Thus, decision

\begin{tabular}{|c|c|c|c|c|}
\hline $\begin{array}{l}\text { PLo } \\
\text { Number }\end{array}$ & $\begin{array}{c}\text { CLOS Achievements (Target } \\
\text { 65\%) }\end{array}$ & $\begin{array}{l}\text { Pls and } \\
\text { Rubrics } \\
\text { (Target 65\%) }\end{array}$ & 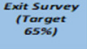 & $\begin{array}{l}\text { Current Student survey ond } \\
\text { Mareting } \\
\text { (rarget } 65 \% \text { ) }\end{array}$ \\
\hline PLO 1 & 67.06 & $87.7 \%$ & $69.79 \%$ & $62.90 \%$ \\
\hline PLO 2 & 65.86 & $49.4 \%$ & $71.44 \%$ & $58.23 \%$ \\
\hline $\mathrm{PLO}_{3}$ & 65.88 & $84.81 \%$ & $67.57 \%$ & $48.74 \%$ \\
\hline PLO 4 & 69.59 & $82.87 \%$ & $67.57 \%$ & $62.33 \%$ \\
\hline PLO 5 & 56.27 & $78.3 \%$ & $68.07 \%$ & $57.41 \%$ \\
\hline PLOG & 80.48 & $92.72 \%$ & $71.27 \%$ & $50.45 \%$ \\
\hline PLO 7 & 53.56 & $55.37 \%$ & 65.59\% & $49.19 \%$ \\
\hline PLO 8 & 65.59 & $64.12 \%$ & $62.29 \%$ & $53.90 \%$ \\
\hline PLO & 62.29 & 78.8696 & $65.49 \%$ & $53.59 \%$ \\
\hline PLO 10 & 64.55 & $66.048 \%$ & $57.17 \%$ & $47.83 \%$ \\
\hline PLO 11 & 64.37 & 81.3896 & 50.1996 & $52.72 \%$ \\
\hline
\end{tabular}
makers can have a CQI improvement plan for each PLO based on the achievements of each assessment method. In addition, the proposed model can provide decision support for the PLOs' achievement percentage using a specific assessment method as shown in Figure 7.

Fig. 5. A general PLOs achievement report

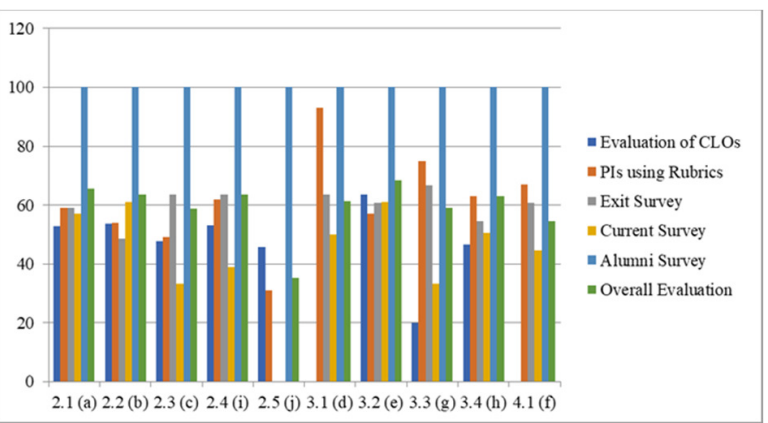

Fig. 6. The general performance of PLO evaluation for all the assessment methods

Evaluation results for each PLOs performance indicator can be provided to support the decisions of the CQI improvement plan for each PLO performance indicator as shown in Figure 8. The proposed model can help decision makers to analyze the achievement of each PLO in each course using a specific 
assessment method. Figure 9 shows the assessment of a specific PLO using CLOs embedded questions in different courses. Thus, the CQI improvement plan for each PLO in each course can be easily recognized and implemented. The proposed model can help program decision makers to analyze the achievements of all courses in a semester mapped to the PLOs as shown in Figure 10. Furthermore, Figures 11-12 show the ability of having a general overview about CLO achievement that can be shown in a semester. Thus, the CQI improvement plan for CLOs in each course can be easily recognized and implemented. The proposed model can help decision makers to analyze the achievement of PLOs across different semesters to find the PLOs achievement trend across time. Figures 13-14 show PLOs achievement across different semesters.

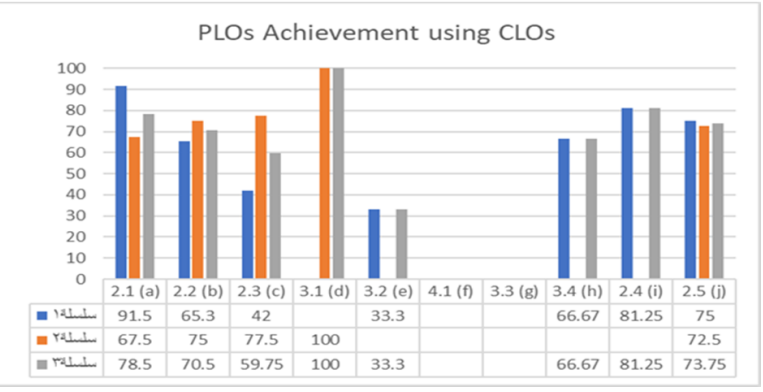

Fig. 7. PLO achievement percentage using CLO assessment method

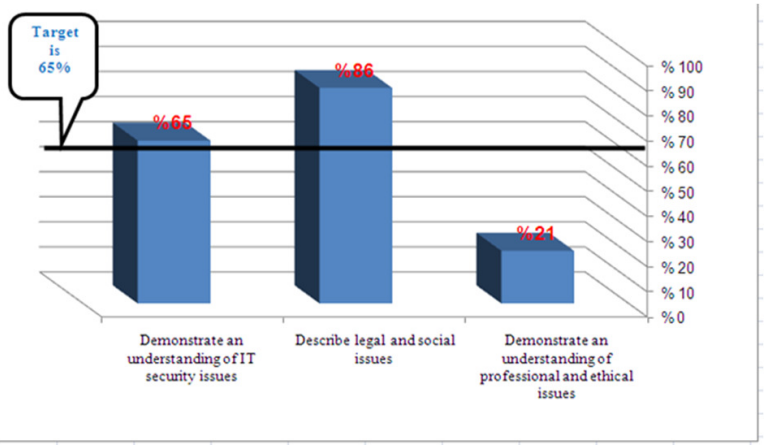

Fig. 8. Evaluation results of PLO performance indicators

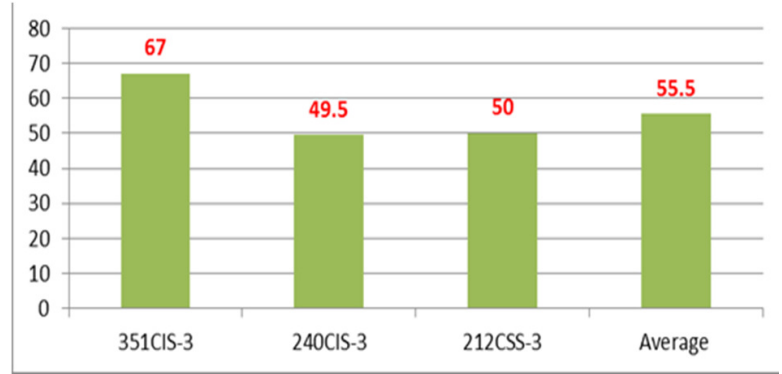

Fig. 9. Assessment of a specific PLO using CLOs embedded questions for three courses

Conversely, the proposed model provides decision support for the authentication and efficiency of the assessment and evaluation process by comparing the results of CLOs assessment and PIs assessment.

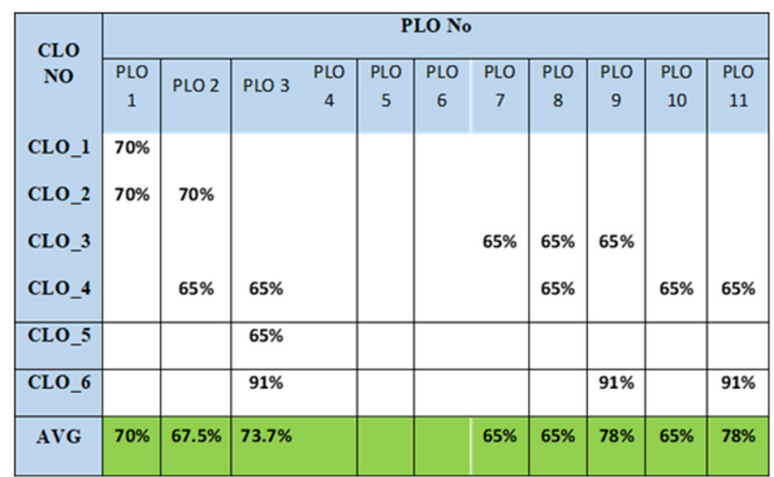

Fig. 10. CLOs achievement mapped to PLOs

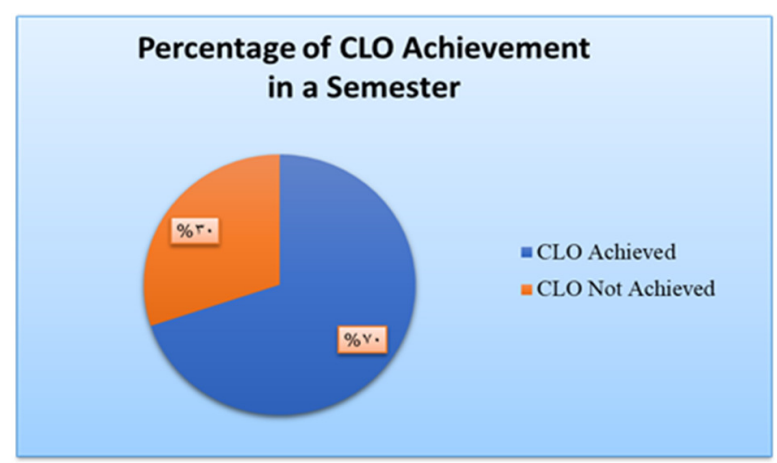

Fig. 11. Comparison of CLO achievement ratio

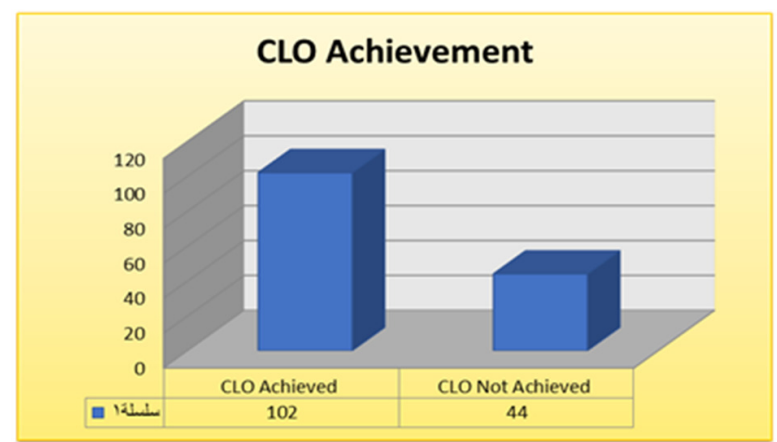

Fig. 12. Achieved CLOs in a semester

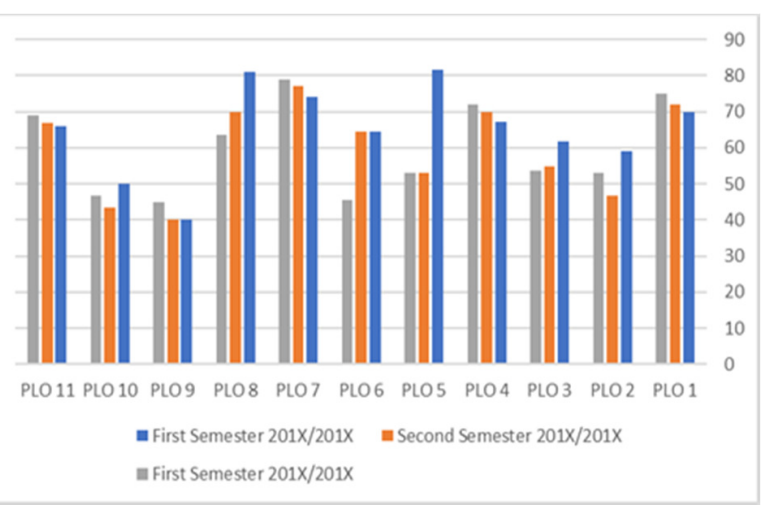

Fig. 13. PLO achievement across different semesters 


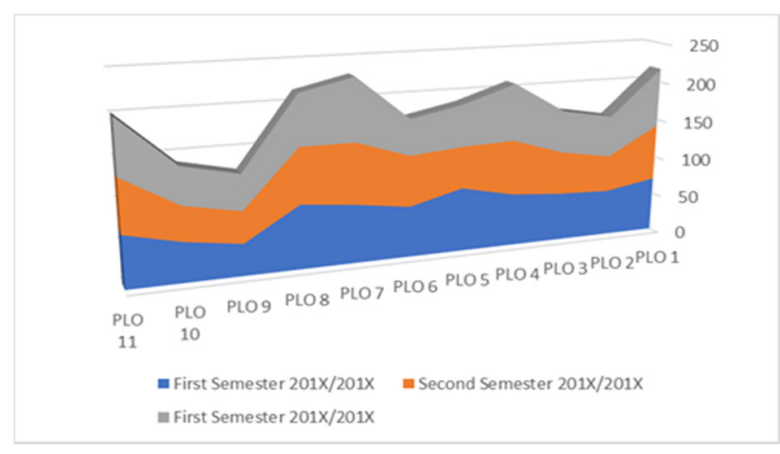

Fig. 14. PLO achievement trend across the time

Figure 15 shows the PLO assessment and evaluation process authentication report. The report provides decision support for the authentication of assessment and evaluation process for each PLO in the program. Additionally, the proposed model can provide a comparison of the assessment, evaluation process, and authentication percentage as shown in Figure 16 to help faculty members check their assessment and evaluation performance in general, in order to take decisions on enhancing their assessment and evaluation skills.

\begin{tabular}{|c|c|}
\hline PLO Number & Assessment and Evaluation Process Authentication \\
\hline PLO 1 & Assessment and Evaluation Process is NOT Accurate \\
\hline PLO 2 & Assessment and Evaluation Process is NOT Accurate \\
\hline PLO 3 & Assessment and Evaluation Process is NOT Accurate \\
\hline PLO 4 & Assessment and Evaluation Process is NOT Accurate \\
\hline PLO 5 & Assessment and Evaluation Process is NOT Accurate \\
\hline PLO 6 & Assessment and Evaluation Process is NOT Accurate \\
\hline PLO 7 & Assessment and Evaluation Process is Accurate \\
\hline PLO 8 & Assessment and Evaluation Process is Accurate \\
\hline PLO 9 & Assessment and Evaluation Process is NOT Accurate \\
\hline PLO 10 & Assessment and Evaluation Process is Accurate \\
\hline PLO 11 & Assessment and Evaluation Process is NOT Accurate
\end{tabular}

Fig. 15. PLO assessment and evaluation process authentication report Assessment and Evaluation Process Authentication

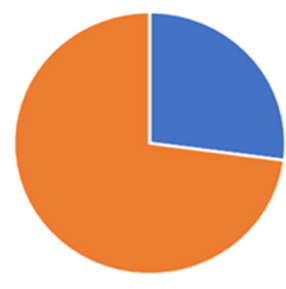

- Accurate " NOT Accurate

Fig. 16. Comparison of PLO assessment and evaluation process authentication percentage

The proposed model provides decision support for the authentication of the continuous improvement process by comparing the results of summative and formative assessments, where the data for summative assessment were collected after the formative assessment. Figure 17 shows the continuous improvement process authentication report for a program. The report provides decision support for the authentication of continuous improvement process for each PLO. Also, the report shows if the continuous improvement process was conducted correctly, or whether it had a problem and needs to be enhanced. In addition, the proposed model can provide a comparison of the continuous improvement process authentication percentage as shown in Figure 18 to help faculty members check their continuous improvement planning performance in general, and in taking decisions on enhancing their continuous improvement planning skills.

\begin{tabular}{|c|l|}
\hline PLO Number & Continuous Improvement Process Authentication \\
\hline PLO 1 & Continuous Improvement Process is Accurate \\
\hline PLO 2 & Continuous Improvement Process is NOT Accurate \\
\hline PLO 3 & Continuous Improvement Process is Accurate \\
\hline PLO 4 & Continuous Improvement Process is Accurate \\
\hline PLO 5 & Continuous Improvement Process is Accurate \\
\hline PLO 6 & Continuous Improvement Process is Accurate \\
\hline PLO 7 & Continuous Improvement Process is Accurate \\
\hline PLO 8 & Continuous Improvement Process is NOT Accurate \\
\hline PLO 9 & Continuous Improvement Process is Accurate \\
\hline PLO 10 & Continuous Improvement Process is Accurate \\
\hline PLO 11 & Continuous Improvement Process is Accurate \\
\hline
\end{tabular}

Fig. 17. PLO continuous improvement process authentication report

Continuous Improvement Process Authentication

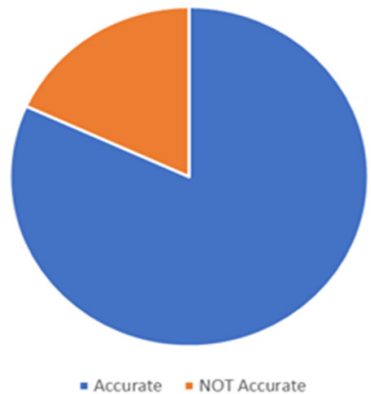

Fig. 18. PLOs continuous improvement process authentication percentage

\section{CONCLUSION}

In this paper, we described the development of a very sustainable and efficient integrated decision support model for enhancing the continuous improvement of academic programs. The implementation of the proposed model validates a high degree of decision support to formulate an authentic CQI for study programs. The proposed model shows efficiency in supporting taking decisions regarding CQI improvement plans for each PLO, PLO performance indicators, courses, and CLOs. Moreover, the proposed model supports decision makers to analyze the achievement of each PLO in each course, the achievement of courses' CLOs that are mapped to the PLOs, and the PLO achievement trend across time. Likewise, the proposed model supports decision makers to guarantee the authentication of the CQI program. Accordingly, the proposed model will support academic programs with decisions to achieve its goals and objectives. 


\section{REFERENCES}

[1] P. G. Altbach, L. Reisberg, L. E. Rumbley, Trends in Global Higher Education: Tracking an Academic Revolution, Report Prepared for the UNESCO 2009 World Conference on Higher Education, Paris, 2009

[2] L. Goff, M. K. Potter, E. Pierre, T. Carey, A. Gullage, E. Kustra, R. Lee, V. Lopes, L. Marshall, L. Martin, J. Raffoul, A. Siddiqui, G. Van Gaste, Learning Outcomes Assessment: A Practitioner's Handbook, Higher Education Quality Council of Ontario, 2015

[3] W. G. Spady, Outcome-Based Education: Critical Issues and Answers, American Assosiation of School Administrators, 1994

[4] T. A. Angelo K. P. Cross, Classroom Assessment Techniques: A Handbook for College Teachers, Jossey-Bass, 1993

[5] J. Biggs, C. Tang, Teaching for Quality Learning at University, McGraw-Hill, 2011

[6] K. L. Harris, International Trends in Establishing the Ttandards of Academic Achievement in Higher Education: An Independent Report and Analysis, Australian Universities Quality Agency, 2009

[7] S. Barrie, C. Hughes, G. Crisp, A. Bennison, AAGLO Summary 1: The ALTC AAGLO project and the international standards agenda, AAGLO, 2011

[8] M. C. Lennon, L. Jonker, AHELO: The Ontario Experience, The Higher Education Quality Council of Ontario, 2014

[9] D. Mladenic, N. Lavrac, M. Bohanec, S. Moyle, Data Mining and Decision Support: Integration and Collaboration, Kluwer Academic Publishers, 2003

[10] L. S. Franz, W. M. Lee, J. C. Van Horn, “An adaptive decision support system for academic resource planning”, Decision Sciences, Vol 12, No. 2, pp. 276-293, 1981

[11] F. Saeed, A. Dixit, "A decision support system approach for accreditation \& quality assurance council at higher education institutions in Yemen", 3rd IEEE International Conference on MOOCs, Innovation and Technology in Education (MITE), Amritsar, India, October 1-2, 2015

[12] M. Sudarma, A. A. K. Oka Sudana, I. Cahya, "Decision Support System for the Selection of Courses in the Higher Education using the Method of Elimination Et Choix Tranduit La Realite", International Journal of Electrical and Computer Engineering, Vol. 5, No. 1, pp. 129-135, 2015

[13] M. Al Shobaki, S. Abu Naser, "Requirements for Applying Decision Support Systems in Palestinian Higher Education Institutions-Applied Study on Al-Aqsa University in Gaza”, International Journal of Information Technology and Electrical Engineering, Vol. 6, No. 4, pp. 42-55, 2017

[14] M. V. de Almeida, J. J. M. Ferreira, F. A. F. Ferreira, "Developing a multi-criteria decision support system for evaluating knowledge transfer by higher education institutions", Knowledge Management Research \& Practice, available at: https://www.tandfonline.com/doi/full/10.1080/ 14778238.2018.1534533, 2018

[15] C. Temponi, "Continuous improvement framework: implications for academia”, Quality Assurance in Education, Vol. 13, No. 1, pp. 17-36, 2005

[16] M. Al-Shargabi, "Decision Support Approach for Enhancing Course Learning Outcomes Achievement and Accuracy of Continuous Improvement Process", International Journal of Advanced Trends in Computer Science and Engineering, Vol. 8, No. 1-3, pp., 320-326, 2019 